\section{Getting into Earth}

\section{Marcia McNutt}

Geophysics: The Earth's Interior. By Jean-Claude De Bremaecker. Wiley: 1985. Pp.342. \$29.95, £30.45.

First the good news. De Bremaecker's introductory account of geophysics is pitched at a simpler level of mathematics than Stacey's Physics of the Earth, while still allowing a more quantitative grasp of the subject than is possible using Bott's The Interior of the Earth. The book is intended for undergraduate earth scientists with one year of calculus and physics, and the mathematical derivations are easy to follow. Interesting historical notes make the text quite readable. I applaud De Bremaecker's use of SI units, but wish he had remained committed to them mgals, kbars and $\mathrm{kg} / \mathrm{cm}^{2}$ all crop up.

Each chapter is divided along the classic branches of geophysics and presents the physics of the problem, methods of solution, a brief description of instrumentation, plus the most recent results. This last feature is a mixed blessing. For a year or two at least it will free the instructor from the burden of remaining abreast of the latest developments in the various fields covered, but it means the book is likely to become rapidly dated; indeed, a few of the conclusions mentioned by the author have ectly with the availability of good recent books on the subject. I was very impressed with the choice of topics and the discussion in the chapter on geomagnetism, much less so with the material on gravity, especially the section on the so-called gravity "inverse problem".

Worse, perhaps, topics from geodesy such as the hydrostatic figure of the Earth, Chandler wobble and precession of the equinoxes are missing, presumably due to the constraint of what can be covered in a one-semester course. This omission is understandable but unfortunate given the increasing influence of space-age geodesy on geodynamics, gravity and seismology. In addition, I found most of the homework problems predictable and uninspired compared to Stacey's inventive exercises.

Still, the book has its strong points. I suggest that instructors wishing to cover the global aspects of geophysics for students not yet comfortable with complex variables, spherical harmonics and Fourier analysis should give it careful consideration.

Marcia McNutt is an Assistant Professor in the Department of Earth, Atmospheric and Planetary Science, Massachusetts Institute of Technology, Cambridge, Massachusetts 02139, USA.

book will certainly learn the elements of how the Earth operates as a natural chemical system. There are a few annoying lapses; for example, the discussion of seawater buffer capacity is inadequate, and in dealing with the natural sulphur cycle too much emphasis is placed on hydrogen sulphide and too little on the role of dimethyl sulphide produced by algae near the ocean surface. On the other hand, the integration of concepts from pure chemistry into an environmental context is well done and organic aspects are particularly clearly presented.

Rather little knowledge of pure chemistry is assumed of the reader and this may limit the usefulness of the book for chemistry undergraduates. It should, however, have a ready audience amongst students studying biology, geology, environmental sciences, physical geography and ecology.

A glossary of terms used in the text is given at the end of the book. But it is a pity that no list of further reading is provided, because I am sure O'Neill's book will fire the imagination of at least some of its readers to study environmental chemistry in greater depth.

Peter Liss is Professor in the School of Environmental Sciences, University of East Anglia, Norwich NR4 7TJ, UK.

\section{IRA PUBLICATIONS}

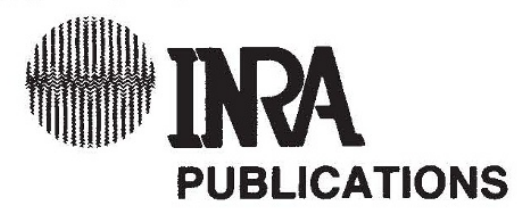

JUST PUBLISHED

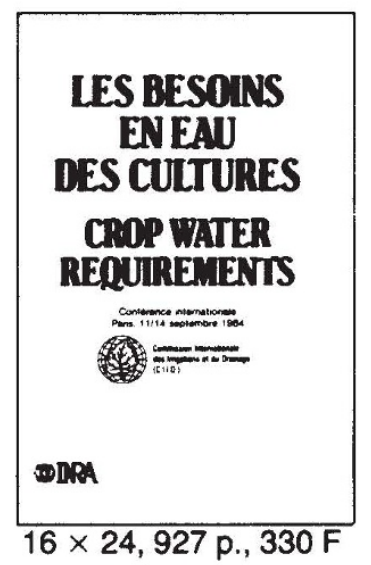

AVAILABLE IN APRIL 1986
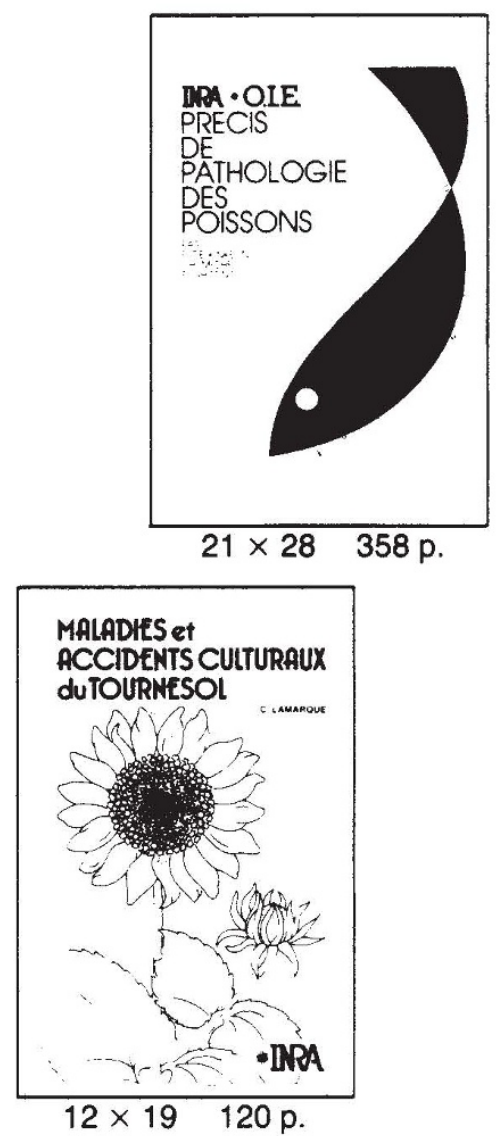

INSTTUT NATONAL DE LA RECHERCHE AGRONOMIQUE SERVICE DES PUBLLCATIONS

Rite de St-Cyr, F-78000 Versailles (France) Télex: INRAPUB 699368F

By and large the author is very successful in achieving his aim, and readers of the 